\title{
KNOWLEDGE MANAGEMENT USING STUDENT FEEDBACK: A STUDY OF ONLINE STUDENTS' LIVED EXPERIENCES ON VIRTUAL TEAMS
}

\author{
Michael F. Lohle, University of Bridgeport, mlohle@bridgeport.edu \\ Steven Terrell, Nova Southeastern University, terrell@nova.edu
}

\begin{abstract}
Introducing group projects in online courses provides an excellent learning laboratory for students to experience what it is like to work on virtual teams. This qualitative study leverages a knowledge base containing feedback captured in a university learning management system from a population of thirty-four students in an online M.B.A. project management course over three semesters to examine the lived experience of students assigned to virtual work teams. Anonymous student discussions about their successes and challenges while collaborating on virtual teams to deliver a final research paper are reviewed. A grounded theory is proposed and best practices provided for instructors interested in including virtual team projects in their own online courses.
\end{abstract}

Keywords: Grounded Theory, Knowledge Management, Virtual Teams, Online Courses, Project Management, Learning Management Systems

\section{INTRODUCTION}

Delivering online courses is challenging so instructors may be hesitant to introduce the additional complexity of administering team projects, removing an opportunity for students to experience working on virtual teams. This study analyzed the lived experience of students who conducted virtual team projects over several semesters and provided a grounded theory and best practices to assist online instructors considering the inclusion of virtual team projects in their courses.

While this was a qualitative study it was also an exercise in knowledge management. Recently thought leaders including Davenport (2015), Skyrme (2011) and Lee (2015) confirmed knowledge management is dead. The analytical approach applied in this study refutes this. Here a university's learning management system (LMS) served as a knowledge database and the primary researcher's analysis resembled the transformation discussed in Nonaka's (1994) Knowledge Creation Theory where the LMS' explicit knowledge in the form of student feedback was transformed into tacit knowledge via the resulting grounded theory and best practices.

\section{PURPOSE}

This study's purpose was to help online instructors conducting student projects using virtual teams. Student feedback during similar projects informed a grounded theory and best practices for effective project initiation.

\section{RESEARCH METHODOLOGY}

Cultivating personal experience provides a foundation for the development of grounded theory (Glaser \& Strauss, 1967). Recording margin notes on interview transcripts, codifying them via a process of "open coding," selecting an "axial code" that stands out from the others and then using that axial code to analyze the "central phenomenon" and generate a grounded theory constituted the steps followed in this study (Creswell, 2007; Glaser \& Strauss).

Discussion feedback was analyzed from thirty-four MBA students given a project to deliver in an online MBA course in project management administered by University of Bridgeport's Ernest C. Trefz School of Business over three eight week semesters. These students were assigned to self-directed work teams and their goal was to deliver a research paper during final week of the course. Project work comprised these assignments: 
- During the first week team members were asked to agree on a mode of collaboration and submit a one page summary that confirmed how they would collaborate and the tools they would use. They also confirmed how they would communicate, specifically the day, time and mode of communication. Finally, they explained how their group would deal with procrastination or underperforming team members.

- During the second week teams submitted a one-paragraph summary of their research paper topics that also listed each team member's role.

- From the third through the seventh weeks each team submitted a weekly status report.

- Teams submitted their research papers during the last week of the course.

The course also included weekly discussion topics. During the third week and after students submitted their first two project assignments the instructor asked this question:

Relate what you have learned about the special demands of project managers and the cultural dimension with your experience in coming together as a team for the team research paper over the first two modules. What have you learned the most? Why?

Relevant student feedback was coded using Microsoft Excel. To ensure anonymity student names were replaced with sequential numerical identification numbers and the primary researcher destroyed the cross-reference table to remove the ability to refer back to the students afterward.

\section{RESULTS}

Margin notes of student response transcripts yielded 166 open codes, which were tallied and sorted in order from the open codes with the most occurrences to the open codes with the least occurrences. Feedback clustered around three groups of open codes, those with more than ten occurrences, those with between nine and five occurrences and those with less than five occurrences. Instances within data cluster 1 comprised $35 \%$ of the total number of open codes while data cluster 2 comprised $52 \%$ and data cluster 3 comprised $13 \%$.

Table 1. Qualitative Coding Analysis

\begin{tabular}{|c|c|c|}
\hline \multirow{4}{*}{$\begin{array}{c}\text { Data Cluster 1, } \\
35 \% \text { of Total }\end{array}$} & Open Code & Tally \\
\hline & Communication & 31 \\
\hline & Accountability & 16 \\
\hline & Schedules & 12 \\
\hline \multirow{13}{*}{$\begin{array}{l}\text { Data Cluster 2, } \\
52 \% \text { of Total }\end{array}$} & Emergent Leadership & 9 \\
\hline & Collaboration & 8 \\
\hline & Priorities & 9 \\
\hline & Appreciation & 7 \\
\hline & Geographic Distribution & 7 \\
\hline & Goal Setting & 7 \\
\hline & Student Profiles & 7 \\
\hline & Assignment & 6 \\
\hline & Support & 6 \\
\hline & Technical Issues & 6 \\
\hline & Hesitation & 5 \\
\hline & Online vs. On Campus & 4 \\
\hline & Strategy & 5 \\
\hline \multirow{11}{*}{$\begin{array}{c}\text { Data Cluster 3, } \\
13 \% \text { of Total }\end{array}$} & Input & 4 \\
\hline & Motivation & 4 \\
\hline & Commitment & 3 \\
\hline & Challenges & 2 \\
\hline & Lack of Authority & 2 \\
\hline & Negotiation & 2 \\
\hline & Coordination & 1 \\
\hline & Culture & 1 \\
\hline & Expectations & 1 \\
\hline & Lack of Familiarity & 1 \\
\hline & Total Open Codes & 166 \\
\hline
\end{tabular}


With thirty-one occurrences or $19 \%$ of the total communication emerged as the study's axial code and is highlighted in gray. The central phenomenon depicts how the other open codes related to communication. This summary discusses the components of data cluster 1 in detail, starting with the axial code, communication and continuing to the next two codes in order of their frequency of occurrence. Then the contents of data clusters 2 and 3 are summarized.

\section{SUMMARY}

Communication. When initiating their virtual team projects student concern about communication was prevalent. Students cited insufficient communication and miscommunication as potential risks for missing deadlines or performing poorly, they were sensitive to how peers from other cultures communicate and how the sender's tone would come across in telephone conversations. Concerns about foreign accents were also mentioned, relevant since University of Bridgeport has a large international student population. Concerns about communicating exclusively via written formats such as e-mail were shared while students using communication methods incorporating visual cues that allowed teammates to interpret each other's body language (e.g. Skype) were pleased with progress. Students also applauded teammates' flexibility in using multiple communication tools and having multiple communication vehicles at their disposal provided comfort. Students also confirmed communicating several times a week spurred progress while some confirmed miscommunication had occurred that adversely impacted progress. Interestingly, Student 20 confirmed it was helpful that the first project assignment emphasized establishing communication and affirmed that not just establishing the mechanism but also a meeting schedule was crucial. A theme running through this feedback was the concern poor communication would threaten project delivery and establishing an effective communication strategy was important. For every positive declaration like this from

Student 21, "My team did a great job establishing various forms of communication," others affirmed deep concern about whether or not their teams would effectively communicate.

Accountability. Team member accountability exhibited the second highest rate of occurrence. Students confirmed their expectations and demanded high teammate accountability. A comment from Student 26 summarized their feedback, "We have a responsibility to our Professor, responsibility to our project and moreso to our team." Students leveraged the discussion thread to publicly hold each other accountable and admonish their peers to succeed. For example, when discussing others' concerns about time zone differences and scheduling conflicts, Student 2 responded, "It's on that person to work that much harder...excuses don't hold weight in my mind." In addition, several students confirmed if one team member did not meet their commitments a "ripple effect" [Student 22] would occur where overall delivery would suffer. Several students were also exasperated teams were expected to meet and start delivering before they were fully exposed to the material. Others were surprised how quickly their teams began to perform.

Schedules. Schedules were an obsession. Student 18 confirmed using their team's delivery schedule fostered team "balance" while others complained coordinating students' schedules was difficult. Students confirmed their professional work schedules impacted their availability and time zone differences were also of concern, despite the reality that the most extreme time difference students contended with over the three semesters studied was two hours. For example, Student 17 complained that coordinating everyone's time schedules rendered response times that "seemed to take forever" while Student 22 said, "I must admit it is a bit tight in terms of timing for me..."

Feedback from the second data cluster supported the first data cluster. Codes are listed and described in descending order of occurrence:

- Emergent Leadership: Nine students confirmed because these teams were self-managed leaders emerged for different tasks as befit their skills and preferences. Only one team assigned a project manager, all others allowed leaders to emerge. This finding supports Jarvenpaa, Knoll and Leidner's (1998) findings that leadership tends to rotate on virtual teams. 
- Collaboration: Students shared anecdotes about initial confusion while others noted establishing effective collaboration was crucial.

- Priorities: Students expressed strong concerns about the project in relation to their other personal, professional and academic demands. Students stated these demands exacted a "big hit" [Student 22] on their availability and they were making sacrifices [Student 26].

- Appreciation: Several students expressed appreciation for their teams.

- Geographic Distribution: Though most hailed from within one hundred miles of the university's campus several students cited logistical concerns when considering their teammates' geographic distribution.

- Goal Setting: Phrases like "powered through" [Student 29] and "goal orientation got us through" [Student 24] appear and students affirmed setting, agreeing and keeping to goals was crucial.

- Student Profiles: Students were pursuing a business degree while others were pursuing a humanities degree and this difference triggered concern. On the other hand Student 15 confirmed that during their team's first meeting teammates discussed their backgrounds which led to a "tremendously helpful" open dialog.

- Assignment: Several students appreciated the instructor's assignment of teams prior to project initiation because this saved considerable time.

- Support: Students affirmed a supportive team fosters positive progress.

- Technical Issues: Feedback for this primarily consisted of Student 15's personal computer issues, "My computer and I have not started out this semester as friends." Others mentioned encountering technical issues but apparently troubleshot them and proceeded without incident.

- Hesitation: Several students hesitated upon learning they would need to engage in a team project because they had poor previous experience on student teams. These comments exemplify this, "I initially dreaded our group project" [Student 33] and "I did all the work...not fun." [Student 2].

- Online vs. On Campus: Students perceived a contradiction between the challenges of conducting team projects during online classes vs. those conducted on campus, implying it is easier to engage in team projects on campus. For instance, Student 30 stated, "It is difficult working on a group project in a nonclassroom setting."

- Strategy: Setting a strategy for success was emphasized by several students.

Feedback from the third data cluster supported the feedback covered earlier and is summarized here in descending order of occurrence. Students felt facilitating the sharing of team member input was critical, motivation and commitment were also cited as important and two students acknowledged anticipated challenges. Considering the self-managed nature of these virtual teams, several students shared concerns about not having the authority to grade their peers and did not feel comfortable relying on and having to share a grade with them. A few confirmed negotiation skills had been required to navigate their first weeks together, others anticipated they would become important as the project progressed. Finally, one student apiece cited concerns about project coordination, cultural differences, the instructor's expectations and the realization that team members had not met each other before. 


\section{CONCLUSIONS}

Though these student projects were conducted in a virtual environment students confirmed communication, accountability and schedules were more important than technical concerns. While somewhat reassuring, this reinforces the instructor's responsibility to actively engage with and orient students when assigning project work in online classes. This theoretical model describes the suggested actions instructors should take during project initiation to ensure their students start well. Its components are described below along with best practices.

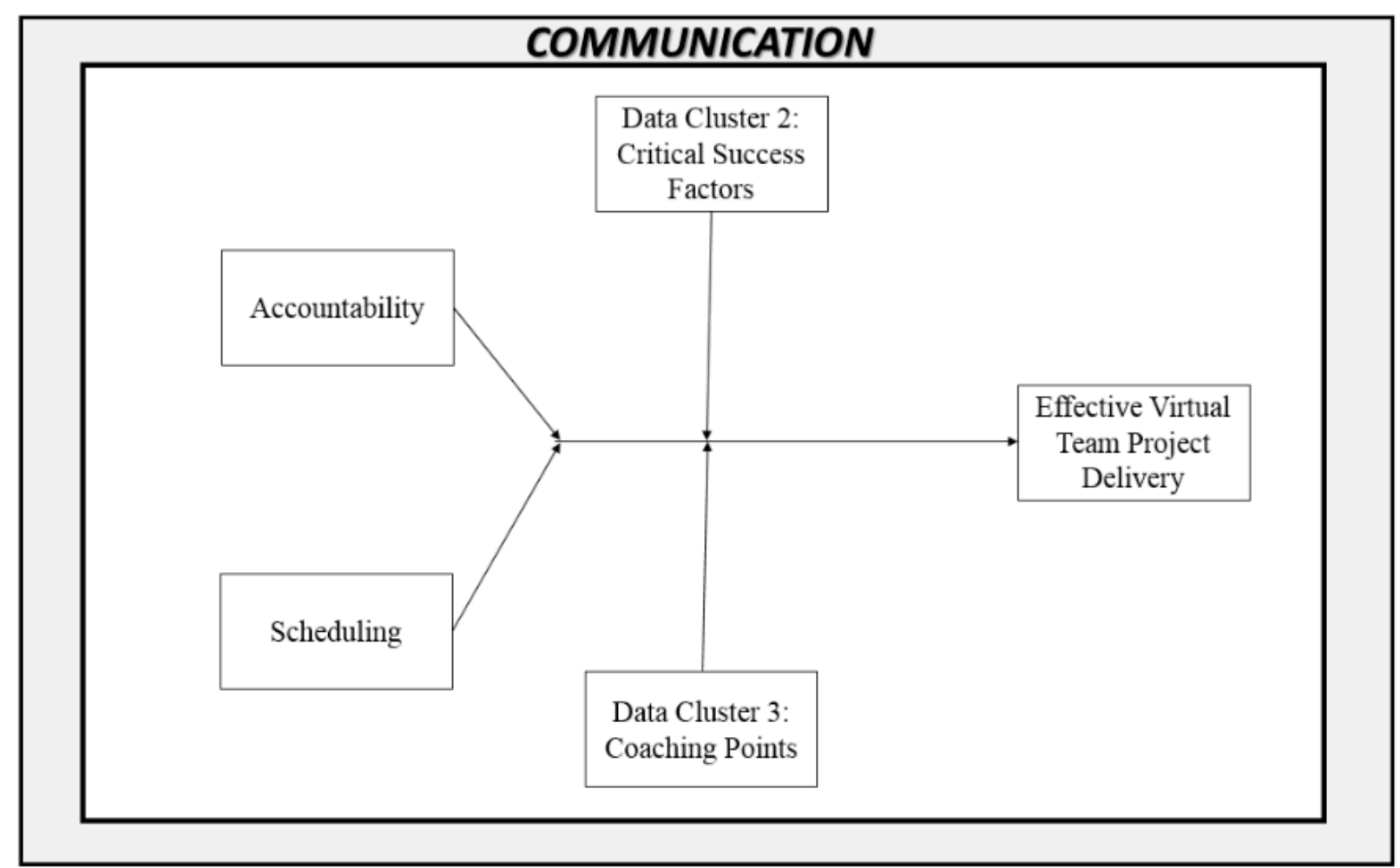

Figure 1. A Grounded Theoretical Model for Student Project Delivery on Virtual Teams.

Communication bounds the model since effective communication is critical. Then, since the goal is to achieve effective project delivery via virtual student teams this becomes the dependent variable while accountability and scheduling, the two other codes most often cited as predictors of success, become the model's two independent variables. While the codes comprising data cluster 2 were not cited as often as the model's independent variables, feedback suggested they are critical success factors so the model adds a moderating variable for them. Similarly, while data cluster 3's codes were not as prevalent as the others having an awareness of them should increase the probability of success so the model adds another moderating variable for coaching points. The decision to depict these critical success factors and coaching points as moderating variables vs. independent variables is one of degree. Feedback indicated the absence of communication, accountability or effective scheduling would prove catastrophic for project delivery while not satisfying some or all of the critical success factors would be painful. On the other hand, while acting on the coaching points should enhance success not doing so would probably not adversely impact delivery.

This model has several implications for online instructors and these best practices are provided to facilitate additional brainstorming. First, ensuring active, effective communication is important so instructors should establish multiple avenues for communication, recommend tools that provide the ability for students to see and interpret visual cues and actively and consistently engage students. Second, reinforcing accountability enhances the probability of success so offering to join team meetings, establishing evaluation criteria that fosters accountability 
and exhorting students to use the various communication mechanisms at their disposal to either privately or publicly escalate details about underperforming students sends a powerful message. Likewise, using the various available feedback mechanisms instructors should convey the perils of allowing scheduling issues to persist and include effective schedule coordination and student availability in their course evaluation rubrics. Then, instructors should step teams through the critical success factors, reiterate them often and assess progress against them. They should also share the coaching points and urge students to keep them in mind as they proceed. Finally, they should invest the time to assign students to teams prior to project initiation and post all relevant information on a visible page on the LMS' course website.

\section{LIMITATIONS}

This study analyzed a snapshot of data three weeks into an eight week online class. While this provides a good understanding of student perceptions during their virtual project teams' initiation phase it does not provide a complete picture of how teams fared throughout the project lifecycle. Fortunately additional feedback was captured in the LMS covering the full project life cycle so a longitudinal study of their progress over time is possible.

\section{RECOMMENTATIONS FOR FUTURE RESEARCH}

Enrollment for this online master's course was primarily comprised of working professionals. Moreover, the project was assigned during a project management course so the students were learning how to manage projects as they delivered. In addition, since the students in this study expressed concerns about the geographic distance between them and time zone differences though the majority of them were local testing this theoretical model on a global scale would be enlightening. It would also be interesting to evaluate it with different cohorts of students in different settings with different curricula.

\section{REFERENCES}

Creswell, J. W. (2007). Qualitative inquiry and research design: Choosing among five approaches (2nd ed.). Thousand Oaks, CA: Sage Publications, Inc.

Davenport, T. (2015, June 24). Whatever happened to knowledge management? The Wall Street Journal. Retrieved July 12, 2016, from http://blogs.wsj.com/cio/2015/06/24/whatever-happened-to-knowledge-management/

Glaser, B. G., \& Strauss, A. L. (1967). The discovery of grounded theory: Strategies for qualitative research. Chicago, IL: Aldine Publishing Company.

Jarvenpaa, S. L., Knoll, K., \& Leidner, D. E. (1998). Is anybody out there? Antecedents of trust in global virtual teams. Journal of Management Information Systems, 14(4), 29-64.

Lee, J. (2015). Why death of chief knowledge officers is a good thing. The APQC Blog. Retrieved 7/12/2016 from https://www.apqc.org/blog/why-death-chief-knowledge-officers-good-thing

Skyrme, D. (2011). The evolution of knowledge management. David Skyrme Associates. Retrieved 7/12/2016 from http://www.skyrme.com/kmbasics/evolution.htm 